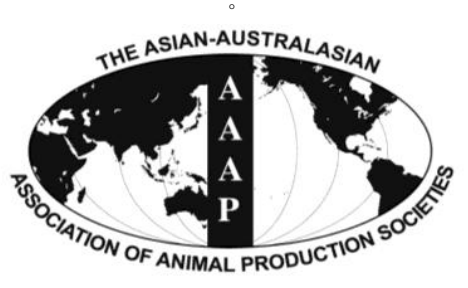

Open Access

Asian Australas. J. Anim. Sci.

Vol. 28, No. 2 : 223-230 February 2015

http://dx.doi.org/10.5713/ajas.14.0328

www.ajas.info

pISSN 1011-2367 elSSN 1976-5517

\title{
Effects of Dietary Coconut Oil as a Medium-chain Fatty Acid Source on Performance, Carcass Composition and Serum Lipids in Male Broilers
}

\author{
Jianhong Wang, Xiaoxiao Wang, Juntao Li, Yiqiang Chen, Wenjun Yang, and Liying Zhang* \\ State Key Laboratory of Animal Nutrition, China Agricultural University, Beijing 100193, China
}

\begin{abstract}
This study was conducted to investigate the effects of dietary coconut oil as a medium-chain fatty acid (MCFA) source on performance, carcass composition and serum lipids in male broilers. A total of 540, one-day-old, male Arbor Acres broilers were randomly allotted to 1 of 5 treatments with each treatment being applied to 6 replicates of 18 chicks. The basal diet (i.e., R0) was based on corn and soybean meal and was supplemented with $1.5 \%$ soybean oil during the starter phase (d 0 to 21 ) and $3.0 \%$ soybean oil during the grower phase (d 22 to 42). Four experimental diets were formulated by replacing $25 \%, 50 \%, 75 \%$, or $100 \%$ of the soybean oil with coconut oil (i.e., R25, R50, R75, and R100). Soybean oil and coconut oil were used as sources of long-chain fatty acid and MCFA, respectively. The feeding trial showed that dietary coconut oil had no effect on weight gain, feed intake or feed conversion. On $\mathrm{d} 42$, serum levels of total cholesterol, low-density lipoprotein cholesterol, and low-density lipoprotein/high-density lipoprotein cholesterol were linearly decreased as the coconut oil level increased $(\mathrm{p}<0.01)$. Lipoprotein lipase, hepatic lipase, and total lipase activities were linearly increased as the coconut oil level increased $(p<0.01)$. Abdominal fat weight/eviscerated weight $(p=0.05)$, intermuscular fat width $(\mathrm{p}<0.01)$ and subcutaneous fat thickness $(\mathrm{p}<0.01)$ showed a significant quadratic relationship, with the lowest value at $\mathrm{R} 75$. These results indicated that replacement of $75 \%$ of the soybean oil in diets with coconut oil is the optimum level to reduce fat deposition and favorably affect lipid profiles without impairing performance in broilers. (Key Words: Broiler, Medium-chain Fatty Acid, Growth Performance, Carcass Composition, Serum Lipid)
\end{abstract}

\section{INTRODUCTION}

Poultry meat is an important food resource for many people. Consumers are becoming increasingly concerned about the nutritional and health aspects of their food (Yeung and Morris, 2001). However, genetic selection for more rapid growth of modern broiler chickens has caused undesirable consequences, including excessive carcass fatness (Rabie and Szilágyi, 1998). This increase is undesirable to consumers because of relationships between fat consumption and the risk of cardiovascular diseases and cancer have been demonstrated (Cherian et al., 1996).

Fat deposition in modern broilers comes mainly from dietary lipids (Sanz, 2000). Therefore, it may be possible to achieve the desired characteristics of rapid growth and

* Corresponding Author: Liying Zhang. Tel: +86-10-6273-3588, Fax: +86-10-6273-3688, E-mail: zhangliying01@ sina.com Submitted May 7, 2014; Revised Aug. 5, 2014; Accepted Aug. 23, 2014 optimum carcass composition by manipulating the composition of the lipids provided in the diet.

There are many studies dealing with the alteration of metabolic responses and carcass fat deposition resulting from increased unsaturated fatty acid (UFA) levels in diets (Nuernberg et al., 2011; Royan et al., 2011). However, the use of unsaturated fat will result in the need for additional vitamin $\mathrm{E}$ and other antioxidants which will inevitably increase diet cost. Thus, new beneficial solutions to maximize growth rate and to minimize undesirable fat accumulation need to be identified.

Coconut oil is a highly saturated oil (about 90\%), and $60 \%$ of its total fatty acid composition are medium-chain fatty acid (MCFA) with a chain length of 6 to 12 carbon atoms (Bhatnagar et al., 2009), which are absorbed directly into the portal circulation without re-esterification in intestinal cells (Ferreira et al., 2012). The MCFA are partly independent of the carnitine transport mechanism into the mitochondria of the liver and are rapidly and exclusively 
oxidized for the production of energy (Rubin et al., 2000). In contrast, the long-chain fatty acid (LCFA) commonly found in most diets are incorporated into chylomicrons after being absorbed in the intestine where they are subjected to re-esterification and then reach the bloodstream via the lymphatic system (Ferreira et al., 2012). Most LCFA are stored in the adipose tissue (Rego Costa et al., 2012).

As a result of their faster metabolism and reduced storage in adipocytes, MCFA have been reported to reduce fat deposition (Han et al., 2003; St-Onge et al., 2003; Takeuchi et al., 2006) and improve serum lipid profiles (Xie et al., 2002; Han et al., 2003) in humans and rats. However, few studies have been conducted in broiler chickens excepting that MCFA reduced weight gain (Solis de los Satntos et al., 2008) and that coconut oil could improve fat digestion and performance values during the coccidiosis infection (Adams et al., 1996). Therefore, the objectives of this study were to determine the effects of feeding coconut oil as a MCFA source on performance, carcass characteristics and serum lipid metabolic parameters in broilers.

\section{MATERIALS AND METHODS}

\section{Bird management}

A total of 540, one-day-old, male Arbor Acres broiler chicks (average weight $42.4 \mathrm{~g}$ ), were obtained from the Arbor Acres Poultry Breeding Company (Beijing, China). The birds were individually wing-banded and housed 6 to a wired-floored cage, measuring $90 \times 60 \mathrm{~cm}$ with a height of $40 \mathrm{~cm}$, equipped with individual feeders and water nipples. Three cages were grouped as one replicate resulting in 6 replicates of 18 birds per treatment. The birds received continuous light. Feed and water were provided ad libitum. The room temperature was set at $35^{\circ} \mathrm{C}$ for the first $3 \mathrm{~d}$ and then was gradually reduced by $3^{\circ} \mathrm{C}$ per week until it reached $24^{\circ} \mathrm{C}$. The relative humidity of the feeding room was maintained between $50 \%$ and $70 \%$. Immunization programs including Newcastle Disease vaccine (inoculated on $\mathrm{d} 7$ and 21) and inactivated Infectious Bursal Disease vaccine (inoculated on $\mathrm{d} 14$ and 28). The animal welfare committee of China Agricultural University (Beijing, China) approved the animal care protocol used for this experiment.

\section{Experimental diets}

Birds were randomly allotted to 1 of 5 treatments for 42 d. Soybean oil and coconut oil were used as sources of LCFA and MCFA, respectively, in the formula. The oil sources were supplemented at $1.5 \%$ of the diet during the starter phase ( 0 to $21 \mathrm{~d}$ ) and at $3.0 \%$ of the diet during the grower phase (22 to $42 \mathrm{~d}$ ). The diets were based on corn and soybean meal and were supplemented with either soybean oil (i.e., R0), or with coconut oil replacing of $25 \%$, $50 \%, 75 \%$, or $100 \%$ of the soybean oil (i.e., R25, R50, R75, and R100). The coconut oil was substituted for soybean oil on an equal weight basis. Therefore, the concentration of total fat in all diets was equal. The diets were formulated to meet or exceed the nutrient requirements of broiler chickens (NRC, 1994; Table 1).

Diets were analyzed for crude protein, ether extract, calcium and total phosphorus (AOAC, 2000). Lysine was determined after a 24-h hydrolysis with $6 \mathrm{~N} \mathrm{HCl}$ at $110^{\circ} \mathrm{C}$ (AOAC, 2000) using an Amino Acid Analyzer (Hitachi L8900, Tokyo, Japan). Methionine were determined as methionine sulfone acid after cold performic acid oxidation and a 24-h hydrolysis with $7.5 \mathrm{~N} \mathrm{HCl}$ at $110^{\circ} \mathrm{C}$ (AOAC, 2000) using an Amino Acid Analyzer (Hitachi L-8900, Tokyo, Japan).

The fatty acid profiles of both oil sources and diets were determined by gas chromatography (Agilent Technologies 6890 series, Wilmington, DE, USA) following the procedures of Sukhija and Palmquist (1988).

\section{Performance}

Mortality was recorded daily and averaged less than $1 \%$ across treatments. Bird weight and feed disappearance were monitored on d 21 and 42. These values were used to calculate body weight gain, feed intake and feed conversion for the periods d 0 to 21 , d 21 to 42 , and the overall experiment.

\section{Slaughter and sample collection}

At the end of each feeding phase, one randomly chosen bird from each replicate $(\mathrm{N}=6)$ was bled via heart puncture using 9-mL vacuum tubes without anticoagulant after a 12$\mathrm{h}$ fast. The samples were immediately centrifuged at 1,500 $\times \mathrm{g}$ for $15 \mathrm{~min}$. Serum was decanted into individual $2 \mathrm{~mL}$ polypropylene tubes, and stored at $-20^{\circ} \mathrm{C}$ for future analyses of glucose (Kit number 315-500; Sigma-Aldrich Chemical Co., St. Louis, MO, USA). The total cholesterol, triglyceride, high-density lipoprotein (HDL) cholesterol, and low-density lipoprotein (LDL) cholesterol levels in serum were determined spectrophotometrically (Bayer Diagnostics Manufacturing Ltd., Dublin, Ireland) using commercial kits (Biosino Biotechnology and Science Inc., Beijing, China; Catalog numbers 0180, 0221, 0215, and 0200). Free fatty acid (FFA) concentration was determined by a colorimetric method (Kit number 750; Huaying Biotechnology and Science Inc., Beijing, China).

Apolipoproteins A (apoA) and B (apoB) were measured in serum using an immunoturbidimetric reaction (UNI-KIT apoA and UNI-KIT apoB, Roche, Basel, Switzerland) and antiserum raised in sheep and rabbits. Malate dehydrogenase, lipoprotein lipase, hepatic lipase and total lipase activities were measured colorimetry (Huaying 
Table 1. Ingredient composition and nutrient content of diets (\% as fed)

\begin{tabular}{|c|c|c|c|c|c|c|c|c|c|c|}
\hline \multirow{2}{*}{ Items } & \multicolumn{5}{|c|}{ Starter phase (d 0 to 21$)$} & \multicolumn{5}{|c|}{ Grower phase (d 22 to 42 ) } \\
\hline & $\mathrm{R} 0^{1}$ & $\mathrm{R} 25$ & R50 & R75 & R100 & R0 & $\mathrm{R} 25$ & R50 & R75 & R100 \\
\hline \multicolumn{11}{|l|}{ Ingredient (\%) } \\
\hline Corn & 60.13 & 60.13 & 60.13 & 60.13 & 60.13 & 61.53 & 61.53 & 61.53 & 61.53 & 61.53 \\
\hline Soybean meal & 32.50 & 32.50 & 32.50 & 32.50 & 32.50 & 31.70 & 31.70 & 31.70 & 31.70 & 31.70 \\
\hline Fish meal & 2.00 & 2.00 & 2.00 & 2.00 & 2.00 & 0.00 & 0.00 & 0.00 & 0.00 & 0.00 \\
\hline Soybean oil & 1.50 & 1.13 & 0.75 & 0.37 & 0.00 & 3.00 & 2.25 & 1.50 & 0.75 & 0.00 \\
\hline Coconut oil & 0.00 & 0.37 & 0.75 & 1.13 & 1.50 & 0.00 & 0.75 & 1.50 & 2.25 & 3.00 \\
\hline Dicalcium phosphate & 1.50 & 1.50 & 1.50 & 1.50 & 1.50 & 1.70 & 1.70 & 1.70 & 1.70 & 1.70 \\
\hline Limestone & 1.34 & 1.34 & 1.34 & 1.34 & 1.34 & 1.15 & 1.15 & 1.15 & 1.15 & 1.15 \\
\hline Sodium chloride & 0.30 & 0.30 & 0.30 & 0.30 & 0.30 & 0.30 & 0.30 & 0.30 & 0.30 & 0.30 \\
\hline DL-methionine (98\%) & 0.23 & 0.23 & 0.23 & 0.23 & 0.23 & 0.12 & 0.12 & 0.12 & 0.12 & 0.12 \\
\hline Vitamin-mineral premix ${ }^{2}$ & 0.50 & 0.50 & 0.50 & 0.50 & 0.50 & 0.50 & 0.50 & 0.50 & 0.50 & 0.50 \\
\hline \multicolumn{11}{|l|}{ Nutrient content $(\%)^{3}$} \\
\hline $\mathrm{ME}(\mathrm{kcal} / \mathrm{kg})$ & 3,010 & 3,010 & 3,010 & 3,010 & 3,010 & 3,060 & 3,060 & 3,060 & 3,060 & 3,060 \\
\hline $\mathrm{CP}$ & 21.54 & 21.68 & 21.73 & 21.49 & 21.51 & 20.02 & 20.16 & 20.19 & 20.05 & 20.10 \\
\hline Ether extract & 4.51 & 4.52 & 4.61 & 4.49 & 4.54 & 6.18 & 6.13 & 6.17 & 6.20 & 6.22 \\
\hline Calcium & 1.02 & 0.99 & 1.01 & 0.97 & 0.95 & 0.91 & 0.93 & 0.92 & 0.94 & 0.91 \\
\hline Total phosphrous & 0.68 & 0.62 & 0.60 & 0.67 & 0.63 & 0.66 & 0.66 & 0.62 & 0.69 & 0.64 \\
\hline Lysine & 1.21 & 1.21 & 1.23 & 1.20 & 1.19 & 1.09 & 1.08 & 1.08 & 1.10 & 1.09 \\
\hline Methionine & 0.57 & 0.54 & 0.51 & 0.57 & 0.55 & 0.43 & 0.42 & 0.40 & 0.45 & 0.42 \\
\hline \multicolumn{11}{|c|}{ Fatty acid profile (\% of total fatty acids) } \\
\hline MCFA & 1.85 & 5.80 & 9.79 & 13.82 & 17.89 & 0.45 & 6.16 & 11.95 & 17.83 & 23.80 \\
\hline LCFA & 98.15 & 94.20 & 90.21 & 86.18 & 82.11 & 99.55 & 93.85 & 88.05 & 82.17 & 76.21 \\
\hline SFA & 22.60 & 27.53 & 32.51 & 37.55 & 42.63 & 20.82 & 27.96 & 35.20 & 42.55 & 50.00 \\
\hline MUFA & 24.48 & 23.42 & 22.36 & 21.28 & 20.19 & 25.74 & 24.21 & 22.67 & 21.11 & 19.52 \\
\hline PUFA & 52.92 & 49.05 & 45.13 & 41.18 & 37.18 & 53.44 & 47.83 & 42.13 & 36.35 & 30.49 \\
\hline UFA & 77.40 & 72.47 & 67.49 & 62.45 & 57.37 & 79.18 & 72.04 & 64.81 & 57.46 & 50.00 \\
\hline UFA/SFA & 3.43 & 2.63 & 2.08 & 1.66 & 1.35 & 3.80 & 2.58 & 1.84 & 1.35 & 1.00 \\
\hline
\end{tabular}

ME, metabolizable energy; CP, crude protein; MCFA, medium-chain fatty acid; LCFA, long-chain fatty acid; SFA, saturated fatty acid; MUFA, monounsaturated fatty acid; PUFA, polyunsaturated fatty acid; UFA, unsaturated fatty acid.

${ }^{1} \mathrm{R} 0=$ soybean oil; $\mathrm{R} 25=25 \%$ coconut oil and $75 \%$ soybean oil; R50 $=50 \%$ coconut oil and $50 \%$ soybean oil; R75 $=75 \%$ coconut oil and $25 \%$ soybean oil; R100 = coconut oil.

${ }^{2}$ Provided the following per kilogram of diet: zinc, $60 \mathrm{mg}$; iron, $95 \mathrm{mg}$; copper, $10 \mathrm{mg}$; iodine, $0.35 \mathrm{mg}$; selenium, $0.3 \mathrm{mg}$; vitamin A, 10,000 IU; vitamin $\mathrm{D}_{3}, 2,750 \mathrm{IU}$; vitamin E, $30 \mathrm{IU}$; vitamin $\mathrm{K}_{3}, 2 \mathrm{mg}$; vitamin $\mathrm{B}_{12}, 1.3 \mathrm{mg}$; riboflavin, $6 \mathrm{mg}$; nicotinic acid, $40 \mathrm{mg}$; pantothenic acid, $12 \mathrm{mg}$; pyridoxine, 3 $\mathrm{mg}$; biotin, $0.2 \mathrm{mg}$; choline chloride, $800 \mathrm{mg}$.

${ }^{3}$ All nutrient levels except ME were analyzed, and values are the means of duplicate determinations. The ME values were calculated using the ME of ingredients obtained from (NRC, 1994), and multiplying these by their inclusion level in the diet and summing the results.

Biotechnology and Science Inc., China) using a Hitachi Auto-Analyzer (Hitachi 7060, Tokyo, Japan). Serum adiponectin, leptin, insulin, and glucagon were measured using the R-911 Automatic Radioimmunoassay Counter (China University of Technology Industrial Corporation, Hefei, China).

After blood sampling on $\mathrm{d} 42$, the birds which were blood sampled were slaughtered, defeathered, processed (removal of heart and feet), and eviscerated. The abdominal adipose pad (including fat surrounding the gizzard, Bursa of Fabricius, cloaca, and adjacent muscles), breast muscle and leg muscles from each bird were collected and weighed. Carcass dressing percentage was expressed as a percentage of body weight. A vernier caliper was used to measure the subcutaneous fat thickness after skin incision at the dorsal midline in front of the caudal vertebrae and intermuscular fat width at the end of the sternum xiphoid.

\section{Statistical analysis}

Analysis of variance was conducted using pen means. All data were analyzed by analysis of variance using the general linear model procedure of SAS (SAS Institute, 1999). Orthogonal polynomial contrasts were used to test for linear and quadratic effects of MCFA inclusion. Significance was considered at $\mathrm{p}<0.05$.

\section{RESULTS}

\section{Fatty acid profile of oil sources}

Coconut oil was highly saturated $(72.52 \mathrm{~g} / 100 \mathrm{~g})$ and 
$47.32 \mathrm{~g}$ of the fatty acid (per $100 \mathrm{~g}$ ) were 6 to 12 carbon atoms in length (i.e., MCFA), which included $36.95 \mathrm{~g}$ lauric acid (C12:0), $4.67 \mathrm{~g}$ capric acid (C10:0), and trace amounts of caprylic acid (C8:0) and caproic acid (C6:0), whereas soybean oil had almost no MCFA (Table 2). Soybean oil was higher in polyunsaturated $(51.60 \mathrm{~g} / 100 \mathrm{~g})$ and monounsaturated $(19.90 \mathrm{~g} / 100 \mathrm{~g})$ fatty acid, but lower in saturated $14.62(\mathrm{~g} / 100 \mathrm{~g})$ fatty acid compared with coconut oil. The total content of the essential fatty acid linoleic $(\mathrm{C} 18: 2)$ and linolenic (C18:3) in soybean oil was 51.50 $\mathrm{g} / 100 \mathrm{~g}$, while these totaled $1.87 \mathrm{~g} / 100 \mathrm{~g}$ in coconut oil.

\section{Performance}

The 42-d feeding study showed that supplying MCFA in the form of coconut oil had no effect $(p>0.05)$ on broiler weight gain, feed intake, or feed conversion in the starter, grower or overall phases (Table 3 ).

\section{Blood biochemical parameters}

On d 21, dietary treatment had no effect $(p>0.05)$ on serum lipid and protein metabolic parameters (Table 4). On $\mathrm{d} 42$, triglyceride was linearly $(\mathrm{p}<0.01)$ and quadratically $(\mathrm{p}$ $=0.04$ ) increased as the level of coconut oil increased. Total cholesterol, LDL cholesterol, and LDL/HDL cholesterol decreased linearly with increasing coconut oil replacement ratio $(\mathrm{p}<0.01)$. The FFA linearly increased $(\mathrm{p}=0.04)$ while apoA and apoB changed in a quadratic pattern $(\mathrm{p} \leq 0.01)$ with increasing coconut oil replacement ratio.

An increase in the coconut oil:soybean oil ratio was associated with a dose-dependent increase in serum lipoprotein lipase, hepatic lipase, and total lipase activities $(\mathrm{p}<0.01)$ both on $\mathrm{d} 21$ and on $\mathrm{d} 42$ (Table 5). On d 21, serum leptin $(\mathrm{p}<0.01)$ and glucagon $(\mathrm{p}<0.01)$ concentrations were linearly decreased and increased, respectively, as the
Table 2. Fatty acid composition of soybean oil and coconut oil ${ }^{1}$

\begin{tabular}{lcc}
\hline Fatty acid profile $(\mathrm{g} / 100 \mathrm{~g})$ & Soybean oil & Coconut oil \\
\hline C6:0 & ND & 0.34 \\
C8:0 & ND & 0.54 \\
C10:0 & ND & 4.67 \\
C12:0 & 0.01 & 36.95 \\
C14:0 & 0.07 & 14.82 \\
C16:0 & 9.35 & 7.84 \\
C16:1 & 0.08 & 0.02 \\
C18:0 & 4.09 & 2.39 \\
C18:1 & 19.65 & 5.68 \\
C18:2n-6 & 45.71 & 1.80 \\
C18:3n-3 & 5.80 & 0.07 \\
C20:0 & 0.37 & 0.08 \\
C20:1 & 0.16 & 0.05 \\
C22:0 & 0.40 & 0.02 \\
Others & 0.41 & 0.25 \\
Medium-chain fatty acid & 0.01 & 47.32 \\
Long-chain fatty acid & 86.11 & 32.81 \\
Monounsaturated fatty acid & 19.90 & 5.74 \\
Polyunsaturated fatty acid & 51.60 & 1.87 \\
Unsaturated fatty acid & 71.50 & 7.61 \\
Saturated fatty acid & 14.62 & 72.52 \\
Unsaturated:saturated fatty acid ratio & 4.89 & 0.01 \\
\hline ND, & &
\end{tabular}

ND, not detected.

${ }^{1}$ Values are the means of analysis conducted in triplicate.

level of coconut oil increased. On d 42, serum insulin was linearly $(\mathrm{p}=0.01)$ and quadratically $(\mathrm{p}=0.04)$ increased, and adiponectin concentration was linearly $(\mathrm{p}<0.01)$ increased as the coconut oil intake increased.

\section{Carcass characteristics}

Abdominal fat weight was linearly decreased as the

Table 3. Effect of dietary coconut oil as a medium-chain fatty acid (MCFA) source on performance of broilers ${ }^{1}$

\begin{tabular}{|c|c|c|c|c|c|c|c|c|c|}
\hline \multirow{2}{*}{ Items } & \multicolumn{5}{|c|}{ Level of coconut oil (\%) } & \multirow{2}{*}{ SEM } & \multicolumn{3}{|c|}{$p$ value } \\
\hline & $\mathrm{R} 0^{2}$ & $\mathrm{R} 25$ & R50 & R75 & R100 & & ANOVA & Linear & Quadratic \\
\hline \multicolumn{10}{|c|}{ Starter phase (d 0 to 21$)$} \\
\hline Weight gain (g/d) & 38.3 & 38.3 & 38.0 & 38.6 & 37.8 & 0.32 & 0.95 & 0.77 & 0.74 \\
\hline Feed intake (g/d) & 44.6 & 44.9 & 44.5 & 44.2 & 43.5 & 0.35 & 0.76 & 0.25 & 0.53 \\
\hline Feed conversion & 1.16 & 1.17 & 1.17 & 1.14 & 1.15 & 0.02 & 0.97 & 0.73 & 0.89 \\
\hline \multicolumn{10}{|c|}{ Grower phase (d 22 to 42 ) } \\
\hline Weight gain $(\mathrm{g} / \mathrm{d})$ & 77.9 & 73.9 & 74.7 & 75.5 & 76.2 & 0.65 & 0.36 & 0.69 & 0.10 \\
\hline Feed intake (g/d) & 141.2 & 141.0 & 138.3 & 141.0 & 138.8 & 2.58 & 0.95 & 0.75 & 0.99 \\
\hline Feed conversion & 1.81 & 1.91 & 1.85 & 1.87 & 1.82 & 0.03 & 0.66 & 0.62 & 0.23 \\
\hline \multicolumn{10}{|c|}{ Overall phase (d 0 to 42 ) } \\
\hline Weight gain (g/d) & 58.1 & 56.1 & 56.4 & 57.1 & 57.0 & 0.37 & 0.47 & 0.62 & 0.16 \\
\hline Feed intake $(\mathrm{g} / \mathrm{d})$ & 92.9 & 93.0 & 91.4 & 92.6 & 91.1 & 1.31 & 0.97 & 0.63 & 0.94 \\
\hline Feed conversion & 1.60 & 1.66 & 1.62 & 1.62 & 1.60 & 0.02 & 0.90 & 0.83 & 0.46 \\
\hline
\end{tabular}

SEM, standard error of the mean; ANOVA, analysis of variance.

${ }^{1}$ Values are the means of 6 replicates of 18 birds.

${ }^{2} \mathrm{R} 0=$ soybean oil; R25 $=25 \%$ coconut oil and $75 \%$ soybean oil; R50 $=50 \%$ coconut oil and $50 \%$ soybean oil; R75 = 75\% coconut oil and $25 \%$ soybean oil; R100 = coconut oil. 
Table 4. Effect of dietary coconut oil as a medium-chain fatty acid (MCFA) source on serum lipid and protein metabolic parameters of broilers $^{1}$

\begin{tabular}{|c|c|c|c|c|c|c|c|c|c|}
\hline \multirow{2}{*}{ Items } & \multicolumn{5}{|c|}{ Level of coconut oil (\%) } & \multirow{2}{*}{ SEM } & \multicolumn{3}{|c|}{$\mathrm{p}$ value } \\
\hline & $\mathrm{R} 0^{2}$ & $\mathrm{R} 25$ & R50 & R75 & R100 & & ANOVA & Linear & Quadratic \\
\hline \multicolumn{10}{|l|}{$\mathrm{d} 21$} \\
\hline Glucose (mmol/L) & 9.8 & 10.4 & 10.9 & 9.4 & 10.8 & 0.51 & 0.35 & 0.69 & 0.27 \\
\hline Triglyceride (mmol/L) & 0.79 & 0.78 & 0.91 & 0.81 & 0.84 & 0.02 & 0.14 & 0.29 & 0.28 \\
\hline Total cholesterol (mmol/L) & 5.18 & 4.08 & 4.90 & 4.48 & 4.30 & 0.18 & 0.31 & 0.29 & 0.70 \\
\hline HDL cholesterol (mmol/L) & 2.25 & 2.14 & 2.57 & 2.37 & 2.17 & 0.06 & 0.09 & 0.83 & 0.08 \\
\hline LDL cholesterol (mmol/L) & 2.55 & 1.67 & 1.91 & 1.74 & 1.74 & 0.17 & 0.46 & 0.20 & 0.35 \\
\hline LDL/HDL cholesterol & 1.14 & 0.79 & 0.78 & 0.74 & 0.81 & 0.08 & 0.49 & 0.21 & 0.22 \\
\hline FFA (nmol/L) & 0.36 & 0.38 & 0.36 & 0.35 & 0.35 & 0.01 & 0.84 & 0.46 & 0.65 \\
\hline Apolipoprotein A (g/L) & 0.15 & 0.13 & 0.14 & 0.14 & 0.14 & 0.00 & 0.60 & 0.85 & 0.34 \\
\hline Apolipoprotein B (g/L) & 0.06 & 0.06 & 0.07 & 0.07 & 0.07 & 0.00 & 0.13 & 0.08 & 0.89 \\
\hline \multicolumn{10}{|l|}{$\mathrm{d} 42$} \\
\hline Glucose $(\mathrm{mmol} / \mathrm{L})$ & 15.1 & 13.6 & 14.2 & 13.0 & 13.9 & 0.47 & 0.40 & 0.21 & 0.28 \\
\hline Triglyceride $(\mathrm{mmol} / \mathrm{L})$ & 0.89 & 0.95 & 1.06 & 1.03 & 1.46 & 0.05 & $<0.01$ & $<0.01$ & 0.04 \\
\hline Total cholesterol (mmol/L) & 3.95 & 4.08 & 3.77 & 3.62 & 3.69 & 0.06 & 0.04 & $<0.01$ & 0.91 \\
\hline HDL cholesterol (mmol/L) & 2.95 & 3.14 & 3.14 & 3.07 & 2.89 & 0.06 & 0.65 & 0.66 & 0.15 \\
\hline LDL cholesterol (mmol/L) & 0.59 & 0.72 & 0.55 & 0.21 & 0.29 & 0.06 & 0.02 & $<0.01$ & 0.52 \\
\hline LDL/HDL cholesterol & 0.20 & 0.24 & 0.20 & 0.07 & 0.11 & 0.02 & 0.02 & $<0.01$ & 0.58 \\
\hline FFA (nmol/L) & 0.34 & 0.35 & 0.35 & 0.36 & 0.39 & 0.01 & 0.05 & 0.04 & 0.31 \\
\hline Apolipoprotein A (g/L) & 0.14 & 0.13 & 0.13 & 0.13 & 0.15 & 0.00 & 0.02 & 0.40 & 0.01 \\
\hline Apolipoprotein B (g/L) & 0.07 & 0.06 & 0.04 & 0.05 & 0.07 & 0.00 & $<0.01$ & 0.88 & $<0.01$ \\
\hline
\end{tabular}

SEM, standard error of the mean; ANOVA, analysis of variance; HDL, high-density lipoprotein; LDL, low-density lipoprotein; FFA, free fatty acid.

${ }^{1}$ Values are the means of 6 birds per treatment.

${ }^{2}$ R0 = soybean oil; R25 = 25\% coconut oil and $75 \%$ soybean oil; R50 = 50\% coconut oil and $50 \%$ soybean oil; R75 = 75\% coconut oil and $25 \%$ soybean oil; R100 = coconut oil.

Table 5. Effect of dietary coconut oil as a medium-chain fatty acid (MCFA) source on serum enzyme activity, adipocytokines and metabolic hormones of broilers ${ }^{1}$

\begin{tabular}{|c|c|c|c|c|c|c|c|c|c|}
\hline \multirow{2}{*}{ Items } & \multicolumn{5}{|c|}{ Level of coconut oil (\%) } & \multirow{2}{*}{ SEM } & \multicolumn{3}{|c|}{$\mathrm{p}$ value } \\
\hline & $\mathrm{R} 0^{2}$ & $\mathrm{R} 25$ & R50 & R75 & R100 & & ANOVA & Linear & Quadratic \\
\hline \multicolumn{10}{|l|}{$\mathrm{d} 21$} \\
\hline Malate dehydrogenase (U/L) & 19.88 & 21.38 & 22.05 & 20.55 & 20.71 & 0.59 & 0.84 & 0.85 & 0.36 \\
\hline Lipoprotein lipase $(\mathrm{U} / \mathrm{mL})$ & 1.14 & 1.45 & 1.47 & 1.42 & 1.62 & 0.05 & 0.02 & $<0.01$ & 0.41 \\
\hline Hepatic lipase (U/mL) & 0.69 & 0.80 & 0.76 & 0.74 & 0.95 & 0.03 & 0.04 & $<0.01$ & 0.29 \\
\hline Total lipase $(\mathrm{U} / \mathrm{mL})$ & 1.83 & 2.25 & 2.23 & 2.16 & 2.57 & 0.05 & 0.02 & $<0.01$ & 0.28 \\
\hline Adiponectin (mg/L) & 11.53 & 11.46 & 12.74 & 12.52 & 12.92 & 0.28 & 0.37 & 0.16 & 0.51 \\
\hline Leptin (ng/mL) & 7.33 & 4.00 & 5.48 & 4.20 & 3.83 & 0.31 & $<0.01$ & $<0.01$ & 0.08 \\
\hline Insulin $(\mu \mathrm{IU} / \mathrm{mL})$ & 16.48 & 19.12 & 16.48 & 16.31 & 15.76 & 0.67 & 0.57 & 0.38 & 0.49 \\
\hline Glucagon (pg/mL) & 74.96 & 76.88 & 81.92 & 91.27 & 93.51 & 1.96 & $<0.01$ & $<0.01$ & 0.70 \\
\hline \multicolumn{10}{|l|}{$\mathrm{d} 42$} \\
\hline Malate dehydrogenase (U/L) & 23.04 & 22.72 & 20.69 & 22.50 & 18.36 & 1.24 & 0.76 & 0.30 & 0.73 \\
\hline Lipoprotein lipase (U/mL) & 1.03 & 1.15 & 1.18 & 1.29 & 1.46 & 0.03 & $<0.01$ & $<0.01$ & 0.30 \\
\hline Hepatic lipase (U/mL) & 0.59 & 0.69 & 0.70 & 0.71 & 0.80 & 0.02 & $<0.01$ & $<0.01$ & 0.72 \\
\hline Total lipase (U/mL) & 1.62 & 1.85 & 1.88 & 2.00 & 2.26 & 0.05 & $<0.01$ & $<0.01$ & 0.49 \\
\hline Adiponectin (mg/L) & 11.04 & 11.69 & 12.25 & 12.62 & 13.83 & 0.26 & $<0.01$ & $<0.01$ & 0.61 \\
\hline Leptin (ng/mL) & 5.90 & 6.70 & 6.63 & 6.09 & 5.76 & 0.20 & 0.50 & 0.54 & 0.13 \\
\hline Insulin $(\mu \mathrm{IU} / \mathrm{mL})$ & 14.53 & 16.41 & 16.55 & 17.13 & 22.32 & 0.95 & 0.05 & 0.01 & 0.04 \\
\hline Glucagon $(\mathrm{pg} / \mathrm{mL})$ & 87.26 & 86.83 & 87.26 & 90.93 & 85.39 & 2.25 & 0.96 & 0.98 & 0.73 \\
\hline
\end{tabular}

SEM, standard error of the mean; ANOVA, analysis of variance.

${ }^{1}$ Values are the means of 6 birds per treatment.

${ }^{2} \mathrm{R} 0=$ soybean oil; R25 $=25 \%$ coconut oil and $75 \%$ soybean oil; R50 $=50 \%$ coconut oil and $50 \%$ soybean oil; R75 = 75\% coconut oil and $25 \%$ soybean oil; R100 = coconut oil. 
coconut oil intake increased at the expense of soybean oil ( $\mathrm{p}$ $=0.05$; Table 6). Abdominal fat weight as a percentage of eviscerated weight $(p=0.05)$, intermuscular fat width $(\mathrm{p}<0.01)$ and subcutaneous fat thickness $(\mathrm{p}<0.01)$ showed a significant quadratic relationship, with the lowest value at R75. Dressing percentage, breast weight/eviscerated weight, and leg weight/eviscerated weight were not affected by coconut oil $(\mathrm{p}>0.05)$.

\section{DISCUSSION}

The results of this study indicate that bird performance was not affected by feeding MCFA in the form of coconut oil. There is little literature regarding the effect of MCFA on broiler production. Solis de los Santos et al. (2008) found that supplementation with $1.4 \%$ caprylic acid (an 8-carbon MCFA) in a regular chick starter diet reduced feed consumption and weight gain, but did not affect feed conversion.

The MCFA has been extensively studied in other animals. Miller et al. (2009) reported that no differences occurred with regard to feed intake, feed efficiency and weight gain in grower and finisher pigs when fed diets with $1 \%$, 3\%, or $6 \%$ of MCFA oil compared with diets containing the same amount of tallow, pig fat or corn oil. However, these results are at variance with those of Dove (1993), who showed that dietary inclusion of 5\% MCFA (weight basis) provided the greatest increase in weight gain and a better feed conversion for post-weaning piglets compared with other sources of fat (soybean oil and animal fat). In studies with rats, no differences were observed between MCFA and LCFA with respect to feed intake (Takeuchi et al., 2006) or weight gain (Shinohara et al., 2005), while some studies showed an increase in feed intake after the addition of MCFA to the diet (Han et al., 2003). Body weight gain and feed intake of White Leghorn chicks decreased with diets containing 10\% MCFA oil (Furuse et al., 1992). Thus, it seems that there is no consensus regarding the effects of MCFA oil on performance of different animal species.

In comparison with LCFA given in the form of soybean oil, MCFA in the form of coconut oil significantly decreased serum total cholesterol, LDL cholesterol concentration and the ratio of LDL to HDL cholesterol, and thereby resulted in a more beneficial lipid profile overall. Coconut oil did not change HDL cholesterol concentrations. Cater et al. (1997) also demonstrated similar HDL cholesterol concentrations on diets rich in MCFA or oleic acid.

The triglyceride-increasing effect of high MCFA (R100 group) observed in the present study is supported by the results of Uzawa et al. (1964) and Hill et al. (1990). However, the effects of MCFA in the form of coconut oil on triglyceride and cholesterol seemed to be contradictory, since triglyceride and cholesterol secretion are regulated in a coordinated manner (Marten et al., 2006). One possible explanation could be that higher MCFA intake in the R100 treatment stimulated insulin secretion and promoted anabolic-related processes (Hill et al., 1990). Thus, increased de novo fatty acid synthesis would lead to an increase in triglyceride production (Hill et al., 1990).

Both apoA and apoB play important roles in the balance of cholesterol and fat transport (Irshad and Dubey, 2005). ApoA is the major protein component of HDL cholesterol in plasma, which helps to clear cholesterol. The lack of an effect on HDL cholesterol in this study indicated that MCFA in the form of coconut oil didn't decrease cholesterol by transporting LDL cholesterol to the liver where it could be reprocessed but must due to another mechanism.

ApoB is the primary apolipoprotein of chylomicrons and LDL cholesterol, which is responsible for carrying cholesterol to tissues (Kane, 1983). The level of apoB is usually regarded as an indicator of heart disease (Contois et al., 2011). Xie et al. (2002) found that apoB was lower with MCFA oil compared with unsaturated LCFA oil when fed to mice. Hepatocyte cultured experiments also showed that

Table 6. Effect of dietary coconut oil as a medium-chain fatty acid (MCFA) source on carcass characteristics of 42 -d-old broilers ${ }^{1}$

\begin{tabular}{|c|c|c|c|c|c|c|c|c|c|}
\hline \multirow{2}{*}{ Items } & \multicolumn{5}{|c|}{ Level of coconut oil (\%) } & \multirow{2}{*}{ SEM } & \multicolumn{3}{|c|}{$\mathrm{p}$ value } \\
\hline & $\mathrm{R} 0^{2}$ & $\mathrm{R} 25$ & R50 & R75 & R100 & & ANOVA & Linear & Quadratic \\
\hline Dressing percentage $(\%)^{3}$ & 74.1 & 75.3 & 72.7 & 74.4 & 71.6 & 1.21 & 0.90 & 0.51 & 0.73 \\
\hline Breast weight/eviscerated weight (\%) & 24.4 & 23.4 & 23.9 & 23.1 & 23.1 & 0.37 & 0.83 & 0.33 & 0.84 \\
\hline Leg weight/eviscerated weight $(\%)$ & 15.8 & 15.8 & 16.0 & 15.9 & 16.3 & 0.12 & 0.41 & 0.13 & 0.47 \\
\hline Abdominal fat weight (g) & 46.3 & 42.9 & 40.9 & 38.8 & 39.6 & 1.32 & 0.05 & 0.05 & 0.39 \\
\hline Abdominal fat weight/eviscerated weight (\%) & 2.22 & 1.98 & 1.83 & 1.46 & 1.92 & 0.21 & 0.04 & 0.09 & 0.05 \\
\hline Subcutaneous fat thickness (mm) & 7.0 & 6.7 & 4.7 & 4.7 & 5.3 & 0.20 & $<0.01$ & 0.22 & $<0.01$ \\
\hline Intermuscular fat width (mm) & 13.6 & 11.1 & 10.9 & 10.3 & 12.5 & 0.41 & 0.05 & 0.60 & $<0.01$ \\
\hline
\end{tabular}

SEM, standard error of the mean; ANOVA, analysis of variance.

${ }^{1}$ Values are the means of 6 birds per treatment.

${ }^{2} \mathrm{R} 0=$ soybean oil; R25 = 25\% coconut oil and $75 \%$ soybean oil; R50 = 50\% coconut oil and $50 \%$ soybean oil; R75 = 75\% coconut oil and $25 \%$ soybean oil; R100 = coconut oil.

${ }^{3}$ Dressing percentage is carcass weight (defeathered and eviscerated) as a percentage of body weight. 
MCFA stimulated apoB less than palmitic acid (Tachibana et al., 2002).

Total lipase is composed of lipoprotein lipase and hepatic lipase, both of which are known to hydrolyze lipids within lipoproteins in the circulation and delivering fatty acid to tissues for storage or oxidation (Kirchgessner et al., 1989). The elevated lipase activities (lipoprotein lipase, hepatic lipase, and total lipase) associated with the attenuating effect of coconut oil on total cholesterol, LDL cholesterol and the ratio of LDL to HDL cholesterol demonstrated that MCFA in the form of coconut oil could promote the digestion and decomposition of lipids through improving the enzyme activities related to fat metabolism to reduce fat deposition, which were confirmed by the increased release of total FFA in the present study.

Adiponectin can stimulate glucose utilization (Yamauchi et al., 2002). Takeuchi et al. (2006) demonstrated that rats fed a MCFA-containing diet had higher levels of adiponectin and lower glucose concentrations in their serum compared with rats fed a LCFA-containing diet. The difference in MCFA level in the diet $(1.45 \%$ in this study vs $20 \%$ in his) may be one of the explanations for the dose response of dietary oil on serum adiponectin with no effect on glucose in the present study.

Leptin is a protein secreted by the adipocytes which maintains the relative stability of body fat by regulating energy metabolism (Hwa et al., 1996). It has been reported that serum leptin concentration is positively correlated with subcutaneous fat (Staiger et al., 2003), which was supported by the results in this study that, both serum leptin on $\mathrm{d} 21$ and subcutaneous fat thickness of 42-d-old broilers were linearly decreased. Glucagon raises blood glucose levels and has been shown to stimulate lipolysis (Heimberg et al., 1969). The coconut oil dose-dependent increase in glucagon in this study would also help to explain the reduced fat deposition of birds fed coconut oil because of the lipolytic activity of glucagon.

The coconut oil in diets had a marked effect on some carcass characteristics. The fat mass-reducing effect of MCFA in the form of coconut oil in this study is in agreement with previous work with rats (Han et al., 2003) and humans (St-Onge et al., 2003). However, soybean oil, well known for its polyunsaturated fatty acid content (UFA:saturated fatty acid $=4.89$ in the present study) could also reduce fat deposition significantly (Royan et al., 2011). The results from this study indicate that medium-chain saturated oil may be more advantageous in abdominal and intermuscular fat reduction than a long-chain unsaturated oil, which is in agreement with the work of St-Onge et al. (2003), who showed that body fat was more significantly reduced with MCFA intervention. One possible explanation for the increasing trend of intermuscular fat width and subcutaneous fat thickness in the R100 treatment could be that coconut oil as the only oil source resulted in an extremely low UFA content, and therefore fatty acid synthesis was enhanced through gluconeogenesis when excess fatty acid were rapidly incorporated into the liver (Shinohara et al., 2002). These findings were also supported by the increased serum triglyceride concentration and insulin secretion (associated with anabolism) in the R100 treatment. In general, the $75 \%$ substitution of coconut oil for soybean oil in present study could effectively reduce fat deposition in broilers without compromising lean meat growth.

In conclusion, based on a consideration of all experiment indexes, replacement of $75 \%$ of soybean oil in diets with coconut oil is suggested to be the optimum level to reduce fat deposition and favorably affect lipid profiles without impairing performance in broilers.

\section{ACKNOWLEDGMENTS}

This study was supported by Ministry of Agriculture (Beijing, China). The authors are grateful to Binzhou Heda Animal Husbandry Co., Ltd. (Binzhou, China) for supplying the coconut oil samples.

\section{REFERENCES}

Adams, B. Y. C., H. A. Vahl, and A. Veldman. 1996. Interaction between nutrition and Eimeria acervulina infection in broiler chickens: Diet compositions that improve fat digestion during Eimeria acervulina infection. Br. J. Nutr. 75:875-880.

AOAC. 2000. Official Methods of Analysis.17th edn. Association of Offical Analytical Chemists, Gaithersburg, MD, USA.

Bhatnagar, A. S., P. K. P. Kumar, J. Hemavathy, and A. G. G. Krishna. 2009. Fatty acid composition, oxidative stability, and radical scavenging activity of vegetable oil blends with coconut oil. J. Am. Oil Chem. Soc. 86:991-999.

Cater, N. B., H. J. Heller, and M. A. Denke. 1997. Comparison of the effects of medium-chain triacylglycerols, palm oil, and high oleic acid sunflower oil on plasma triacylglycerol fatty acids and lipid and lipoprotein concentrations in humans. Am. J. Clin. Nutr. 65:41-45.

Cherian, G., F. W. Wolfe, and J. S. Sim. 1996. Dietary oils with added tocopherols: Effects on egg or tissue tocopherols, fatty acids and oxidative stability. Poult. Sci. 75:423-431.

Contois, J. H., G. R. Warnick, and A. D. Sniderman. 2011. Reliability of low-density lipoprotein cholesterol, non-highdensity lipoprotein cholesterol, and apolipoprotein B measurement. J. Clin. Lipidol. 5:264-272.

Dove, C. R. 1993. The effect of adding copper and various fat sources to the diets of weanling swine on growth performance and serum fatty acid profiles. J. Anim. Sci. 71:2187-2192.

Ferreira, L., K. Lisenko, B. Barros, M. Zangeronimo, L. Pereira, and R. Sousa. 2012. Influence of medium-chain triglycerides on consumption and weight gain in rats: A systematic review. J. Anim. Physiol. Anim. Nutr. 98:1-8.

Furuse, M., R. T. Mabayo, K. Kita, and J. Okumura. 1992. Effect 
of dietary medium chain triglyceride on protein and energy utilization in growing chicks. Br. Poult. Sci. 33:49-57.

Han, J., J. A. Hamilton, J. L. Kirkland, B. E. Corkey, and W. Guo. 2003. Medium-chain oil reduces fat mass and down-regulates expression of adipogenic genes in rats. Obes. Res. 11:734-744.

Heimberg, M., I. Weinstein, and M. Kohout. 1969. The effects of glucagon, dibutyryl cyclic adenosine 3',5'-monophosphate and concentration of free fatty acid on hepatic lipid metabolism. J. Biol. Chem. 244:5131-5139.

Hill, J. O., J. C. Peters, L. L. Swift, D. Yang, T. Sharp, N. Abumrad, and H. L. Greene. 1990. Changes in blood lipids during six days of overfeeding with medium or long chain triglycerides. J. Lipid Res. 31:407-416.

Hwa, J. J., L. Ghibaudi, D. Compton, A. B. Fawzi, and C. D. Strader. 1996. Intracerebroventricular injection of leptin increases thermogenesis and mobilizes fat metabolism in $o b / o b$ mice. Horm. Metab. Res. 28:659-663.

Irshad, M. and R. Dubey. 2005. Apolipoproteins and their role in different clinical conditions: An overview. Indian J. Biochem. Biophys.42:73-80.

Kane, J. P. 1983. Apolipoprotein B: Structural and metabolic heterogeneity. Ann. Rev. Physiol. 45:637-650.

Kirchgessner, T. G., J. C. Chuat, C. Heinzmann, J. Etienne, S. Guil-hot, K. Svenson, D. Ameis, C. Pilon, L. D'Auriol, A. Andalibi, M. C. Schotz, F. Galibert, and A. J. Lusis. 1989. Organization of the human lipoprotein lipase gene and evolution of the lipase gene family. Proc. Natl. Acad. Sci. USA. 86:9647-9651.

Marten, B., M. Pfeuffer, and J. Schrezenmeir. 2006. Medium-chain triglycerides. Int. Dairy J. 16:1374-1382.

Miller, D., Z. Johnston, B. Mullan, J. Pluske, and C. Hansen. 2009. Nutritional manipulation of the somatotropic axis in grower and finisher pigs. Report prepared for the Co-operative Research Centre for an Internationally Competitive Pork Industry. December, 2009. Australia.

Nuernberg, K., B. H. Breier, S. N. Jayasinghe, H. Bergmann, N. Thompson, G. Nuernberg, D. Dannenberger, F. Schneider, U. Renne, M. Langhammer, and K. Huber. 2011. Metabolic responses to high-fat diets rich in n-3 or n-6 long-chain polyunsaturated fatty acids in mice selected for either high body weight or leanness explain different health outcomes. Nutr. Metab. 8:56.

Rabie, M. H. and M. Szilágyi. 1998. Effects of L-carnitine supplementation of diets differing in energy levels on performance, abdominal fat content, and yield and composition of edible meat of broilers. Br. J. Nutr. 80:391-400.

Rego Costa, A. C., E. L. Rosado, and M. Soares-Mota. 2012. Influence of the dietary intake of medium chain triglycerides on body composition, energy expenditure and satiety; A systematic review. Nutr. Hosp. 27:103-108.

Royan, M., G. Y. Meng, F. Othman, A. Q. Sazili, and B. Navidshad. 2011. Effects of conjugated linoleic acid, fish oil and soybean oil on PPARs $(\alpha \& \gamma)$ mRNA expression in broiler chickens and their relation to body fat deposits. Int. J. Mol. Sci. 12: 8581-8595.

Rubin, M., A. Moser, N. Vaserberg, F. Greig, Y. Levy, H. Spivak, Y. Ziv, and S. Lelcuk. 2000. Long-chain fatty acids, in long-term home parenteral nutrition: A double-blind randomized crossover study. Nutrition 16: 95-100.
Sanz, M., C. J. Lopez-Bote, D. Menoyo, and J. M. Bautista. 2000. Abdominal fat deposition and fatty acid synthesis are lower and $\beta$-oxidation is higher in broiler chickens fed diets containing unsaturated rather than saturated fat. J. Nutr. 130: 3034-3037.

SAS Institute Inc. 1999. SAS Users Guide, Version 8.1. SAS Institute Inc., Cary, NC, USA.

Shinohara, H., H. Shimada, O. Noguchi, F. Kubota, and T. Aoyama. 2002. Effect of medium-chain fatty acids-containing dietary oil on hepatic fatty acid oxidation enzyme activity in rats. J. Oleo Sci. 51:621-626.

Shinohara, H., A. Ogawa, M. Kasai, and T. Aoyama. 2005. Effect of randomly interesterified triacylglycerols containing medium- and long-chain fatty acids on energy expenditure and hepatic fatty acid metabolism in rats. Biosci. Biotechnol. Biochem. 69:1811-1818.

Solis de los Santos, F., A. M. Donoghue, K. Venkitanarayanan, M. L. Dirain, I. Reyes-Herrera, P. J. Blore, and D. J. Donoghue. 2008. Caprylic acid supplemented in feed reduces enteric campylobacter jejuni colonization in ten-day-old broiler chickens. Poult. Sci. 87:800-804.

Staiger, H., O. Tschritter, J. Machann, C. Thamer, A. Fritsche, E. Maerker, F. Schick, H. U. Haring, and M. Stumvoll. 2003. Relationship of serum adiponectin and leptin concentrations with body fat distribution in humans. Obes. Res. 11:368-372.

St-Onge, M. P., R. Ross, W. D. Parsons, and P. J. H. Jones. 2003. Medium-chain triglycerides increase energy expenditure and decrease adiposity in overweight men. Obes. Res. 11:395-402.

Sukhija, P. S. and D. L. Palmquist. 1988. Rapid method for determination of total fatty acid content and composition of feedstuffs and feces. J. Agric. Food Chem. 36:1202-1206.

Tachibana, S., K. Sato, T. Takahashi, and Y. Akiba. 2002. Octanoate inhibits very low-density lipoprotein secretion in primary cultures of chicken hepatocytes. Comp. Biochem. Physiol. part A Mol. Integr. Physiol. 132:621-627.

Takeuchi, H., O. Noguchi, S. Sekine, A. Kobayashi, and T. Aoyama. 2006. Lower weight gain and higher expression and blood levels of adiponectin in rats fed medium-chain TAG compared with long-chain TAG. Lipids 41:207-212.

Uzawa, H., G. Schlierf, S. Chirman, G. Michaels, P. Wood, and L.W. Kinsell, G. Fukayama, N-C. Liu, and M. Coelho. 1964. Hyperglyceridemia resulting from intake of medium chain triglycerides. Am. J. Clin. Nutr. 15:365-369.

Xie, C., L. A. Woollett, S. D. Turley, and J. M. Dietschy. 2002. Fatty acids differentially regulate hepatic cholesteryl ester formation and incorporation into lipoproteins in the liver of the mouse. J. Lipid Res. 43:1508-1519.

Yamauchi, T., J. Kamon, Y. Minokoshi, Y. Ito, H. Waki, S. Uchida, S. Yamashita, M. Noda, S. Kita, K. Ueki, K. Eto, Y. Akanuma, P. Froguel, F. Foufelle, P. Ferre, D. Carling, S. Kimura, R. Nagai, B. B. Kahn, and T. Kadowaki. 2002. Adiponectin stimulates glucose utilization and fatty-acid oxidation by activating AMP-activated protein kinase. Nat. Med. 8:12881295.

Yeung, R. M. W. and J. Morris. 2001. Consumer perception of food risk in chicken meat. Nutr. Food Sci. 31: 270-279. 